\title{
A change of heart
}

\section{F. M. Zimmermann • E. van Mierlo • A. Meijer • L. R. Dekker}

Published online: 9 July 2014

(C) The Author(s) 2014. This article is published with open access at Springerlink.com

\section{Question}

A 52-year-old man, without a cardiac medical history, was admitted to the emergency room with chest pain. Physical examination revealed no abnormalities. On presentation, his chest pain had spontaneously disappeared and the ECG did not show significant abnormalities. Thirty minutes later the chest pain reoccurred. A second ECG at that moment is shown in Fig. 1.

What is your diagnosis and can you explain the mechanism?

You will find the answer elsewhere in this issue.

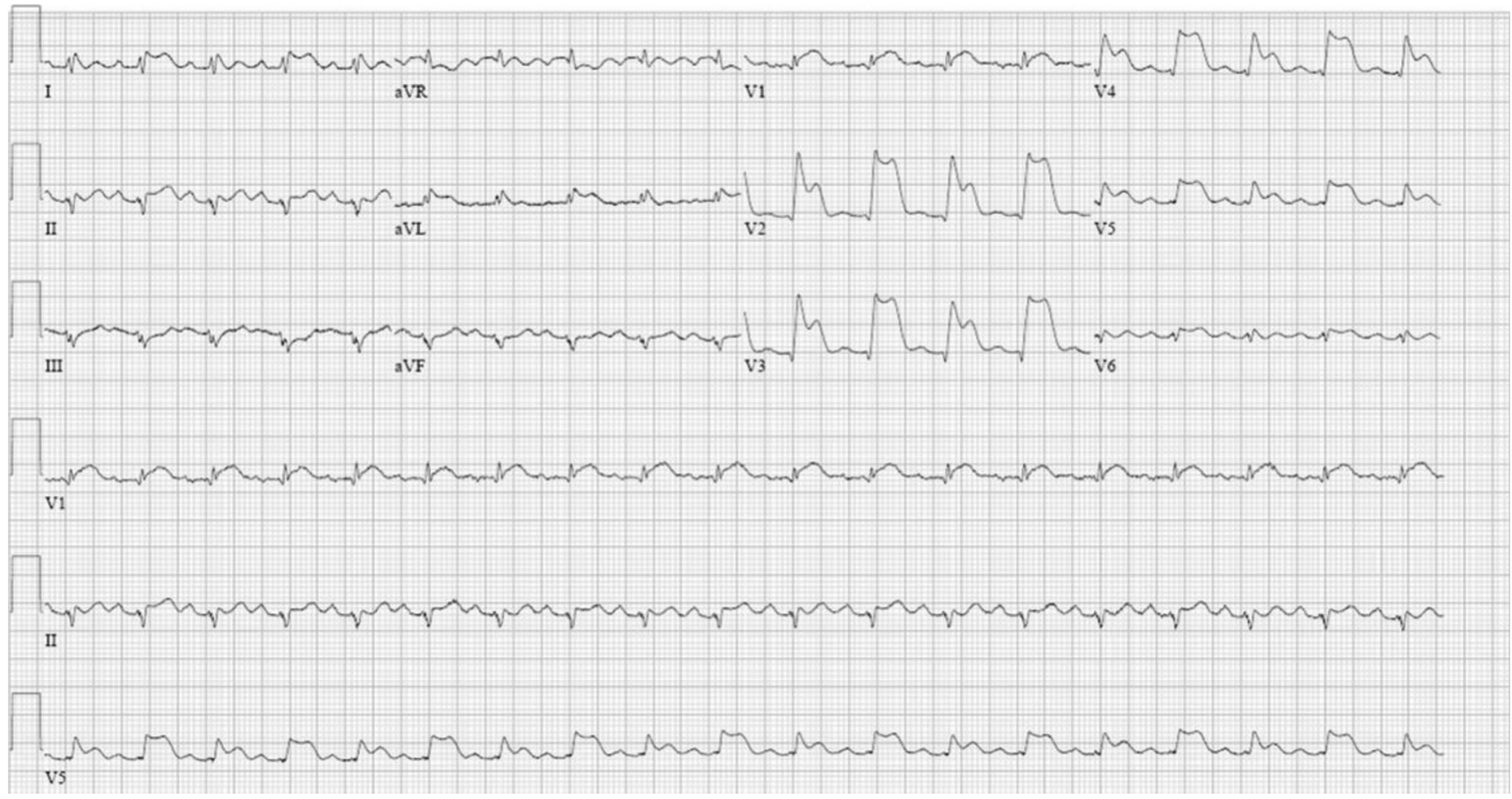

Fig. 1 ECG when the chest pain reoccurred

F. M. Zimmermann $(\bowtie) \cdot$ E. van Mierlo $\cdot$ A. Meijer $\cdot$ L. R. Dekker Department of Cardiology, Catharina Hospital Eindhoven,

Michelangelolaan 2, 5623 EJ Eindhoven, the Netherlands

e-mail: frederik.zimmermann@catharinaziekenhuis.nlcze.nl

F. M. Zimmermann

e-mail: frederik.zimmermann@cze.nl

Open Access This article is distributed under the terms of the Creative Commons Attribution License which permits any use, distribution, and reproduction in any medium, provided the original author(s) and the source are credited. 